\title{
BIM BUSINESS VALUE FOR ASSET OWNERS THROUGH EFFECTIVE ASSET INFORMATION MANAGEMENT
}

\author{
Mustapha Munir, Arto Kiviniemi, Stephen W. Jones, Stephen Finnegan
}

\begin{abstract}
Purpose - The purpose of this paper is to investigate the processes, tools and techniques of strategic asset information management (AIM) for built assets, and how the asset information content enhances the proficiency of asset managers to effectively manage their assets throughout their life cycle by utilising building information modelling (BIM) and asset management (AM) systems. For most asset managers, the problem is not the lack of information about their assets, but the abundance of it, and most especially the absence of established processes and protocols to effectively manage large sets of asset data. Therefore, it is crucial to develop a strategy to control and manage this information in order for asset managers to harness its potential and realise value from their organisation's information assets.
\end{abstract}

Design/methodology/approach - A qualitative case study strategy was used to investigate the effective management of asset data in an AIM system. Seven sets of interviews were conducted and nine respondents were interviewed. These were analysed through qualitative thematic analysis using the NVivo software.

Findings - The paper identifies six dimensions of value that BIM contributes to AM, which are: management, commerce, efficiency, industry, user and technology value. Also, the paper demonstrates that there is real value to be derived by the asset owner from the effective management of asset information. The study highlights that the value of BIM is not inherent but would require many other processes to deliver value to the organisation.

Originality - The key value of the paper is that it identifies important techniques for managing asset data and how asset information is collected, organised, stored, controlled, analysed, secured, shared and reported within a virtual AIM system for strategic management-based decisions.

Paper type - Case Study

KEYWORDS: BIM, AIM, Asset, Management, Information, Value 


\subsection{INTRODUCTION}

Asset owners are continuously seeking opportunities to access accurate, comprehensive and reliable asset information to support the effective and efficient execution of building operations (Matarneh et al., 2019). For many asset owners, the management of built assets alongside other physical assets such as plant and equipment can be an arduous undertaking. The increased adoption of building information modelling (BIM), computer maintenance management systems (CMMS), computer aided facilities management (CAFM), integrated workspace management systems (IWMS) and common data environments (CDE) in asset management (AM) offers opportunities to improve asset information management (AIM) by providing an integrated platform for asset operations through data (Codinhoto and Kiviniemi, 2014; Guillen et al., 2016; Matarneh et al., 2019). Furthermore, the application of BIM has extended to the internet of things (IoT), which is the connection of physical devices embedded with electronics, internet connectivity and automated identification and data capture (AIDC) technologies in asset operations (Dave et al., 2018). However, the diverse nature of these information systems poses a challenge for asset managers who need to efficiently view, operate and manage asset data (Eastman et al., 2011; Teicholz, 2013).

For most asset managers, the problem is not the lack of information about their assets, but the abundance of it and especially the absence of established processes and protocols to effectively manage the large sets of asset data (Lin et al., 2007; Brous et al., 2016). The BIM and AIM systems rely on quality data that is accurate, timely, coherent and complete for critical decision-making. However, data produced by the BIM and AIM systems end up having parameters that are missing the required information because of errors and out of date information. As a result, asset data from the BIM and AIM systems are either lacking or inadequate (Kelly et al., 2013). Therefore, developing a strategy to control and manage organisational information resources is critical for asset managers to be able to harness the potential of realising BIM business value from their information assets.

The documented asset data constitute the information asset, which in turn enhances the ability of managers to make key decisions on their built assets to run them effectively and efficiently (Engelsman, 2007). However, little research has been carried out regarding BIM business value in AM (Love et al., 2013, 2014; Munir et al., 2018). Also, studies related 
to BIM in aspects of AM such as AIM have not been forthcoming. Whilst there is more research emphasis on the optimisation of asset performance and improved decisionmaking, aspects of AIM strategies are neglected (Ouertani et al., 2008). Therefore, further research is needed in this area to investigate models, tools and techniques to better understand the phenomena of business value in relation to information assets, information systems, AIM systems and BIM in AM (Ouertani et al., 2008; Love et al., 2014; Mirarchi et al., 2018).

The purpose of this study is to investigate how the information content collected from built assets generates business value in a BIM-based AIM system. This study focuses on BIM business value derived from existing in-use built assets. Furthermore, it covers strategic aspects for asset owners to consider on new assets to-build. The study seeks to identify the key techniques for managing asset data and how that data are reported for critical decision-making. 


\subsection{LITERATURE REVIEW}

\subsection{BUILDING INFORMATION MODELLING (BIM)}

First, there is a need to define BIM in the context of this study. The term BIM is ambiguous and means different things depending on the context of application (Aranda-Mena et al., 2009). Tse et al. (2005) describe BIM as a powerful tool for the production of drawings in the AEC industry. In contrast, Eastman et al. (2011: 586) define BIM as 'a verb or adjective phrase to describe tools, processes, and technologies that are facilitated by digital machine-readable documentation about a building, its performance, its planning, its construction, and later its operation'. On the other hand, Succar et al. (2007: p. 1) explain $\mathrm{BIM}$ as "a set of interacting policies, processes and technologies producing a methodology to manage the essential building design and project data in digital format throughout the building's life-cycle". Furthermore, Aranda-Mena et al. (2009: p. 2), distinguish between the three perspectives of BIM: the first view assumes that "BIM is a software application"; the second view believes that "BIM is a process for designing and documenting building information"; and the third view holds that BIM "is a whole new approach to practise and advancing the profession which requires the implementation of new policies, contracts, and relationships amongst project stakeholders". From this assertion, it is seen that all the three definitions above have portrayed the three differing perspectives of BIM. Similarly, another term that causes confusion amongst academics and industry experts is the frequent interchange of the term "Modelling" with "Management" in "BIM" to describe a systematic approach to the collection and utilisation of asset information throughout its life cycle (Parsanezhad and Dimyadi, 2014). This study adopts the definition of Succar et al. (2007) and views BIM from the perspective of building information management (Parsanezhad and Dimyadi, 2014) where all relevant building information is integrated or linked within one or more consistent data sets that are generated and delivered to asset managers for the efficient running of built assets. In other words, the study explores the application of BIM in an AM system, which denotes a lifecycle perspective.

\subsection{BIM-BASED ASSET INFORMATION MANAGEMENT}

There is a need to define AM within the context of this study; PAS 55-1 (BSI, 2008, p. 5) defines AM as a set of "systematic and coordinated activities and practices through which an organisation optimally manages its assets, and their associated performance, risks and 
expenditures over their lifecycle for the purpose of achieving its organisational strategic plan". Asset information is created from the action of users when performing AM tasks through the use of techniques, systems and technologies. These sets of information may be the actual intended output produced for a corresponding task or consumed within the same task. This consideration makes AIM a crucial business process for asset owners. In the context of this study, AIM is defined as a set of integrated processes, techniques and technologies involved in collecting, organising, storing, controlling, analysing, securing, sharing and reporting asset information across various sets of information models, in one database or across many databases, from handover to the disposal of a facility. Thus, the study defines the asset information model as a set of integrated data sets, in one model or different, connected models, and containing the essential attributes of the physical assets contained in a facility.

PAS 1192-3 (BSI, 2014) provides specific guidance to asset managers on BIM-based information management processes regarding input, retrieval, output, data types and transfer of data from the asset information model including links to AIM systems. It also provides guidelines for the development of the asset information model which cover data and information definitions, information content and processes for maintaining the asset information model. However, these guidelines are generic and are limited in scope in relation to information content, operational and management-based strategies that support organisational objectives and outcomes. Furthermore, Boyes et al. (2017) demonstrate the AIM practices of a large asset owner through the development of an asset information model, which is coordinated by a central AM team. The study also highlights the challenge in establishing a link between the information produced for the design and construction phases and the asset information needed for building operations. Juan and Zheng (2014) demonstrate the building information interaction process using a hybrid cloud-based approach for a BIM-based information management system. The study highlights the scalability, reliability and potential to facilitate multi-user collaboration using a cloud-based approach to develop a BIM-based AIM system. Li et al. (2014) highlight the utilisation of BIM for the real-time monitoring of the status of a facility and the provision of a database for asset maintenance data. Similarly, Parsanezhad and Dimyadi (2014) highlight the use of information management tools to improve the timely and effective delivery of data for strategic and operational 
management tasks. These studies highlight the need for asset owners to understand the importance of an AIM strategy that would facilitate how asset information could be collected, analysed, stored, managed and reported right through the life cycle of an asset.

Furthermore, Ouertani et al. (2008) suggest that AIM involves two main activities: data capture and data management. Successful AIM strategies are centred on the effective control of information management dynamics within the business ecosystem. Also, the integration of systems and processes is a key requirement for developing a complete AIM solution (Koronios et al., 2005). Consequently, this study focuses on business processes performed by asset managers to optimise existing as-built assets within the domain of an AIM system.

\subsection{INFORMATION VALUE}

In the context of this study, information is defined as data processed for a purpose (Curtis and Cobham, 2008). In other words, information is produced when context and purpose are applied to captured data through defined business processes. In most cases, the more of a certain resource you have the better, but with information, it can be the contrary (Moody and Walsh, 1999). There is a widespread belief that information has many economic properties and harnessing it can represent an organisational asset (Engelsman, 2007). Furthermore, the use of information is seen to increase its value even though it has no real value in its own right (Moody and Walsh, 1999). This is because the value of information depends on the context and application by particular users in specific instances and conditions. As a result, the asset manager requires the delivery of accurate, complete, verified and validated information for BIM-based processes to efficiently maintain the information assets of a facility throughout its life cycle (BuildingSMART, 2018). However, there are challenges that prevent the delivery of such information. One challenge is the large volume and complexity of the data generated by a facility over its life cycle (Pärn et al., 2017). Another challenge is the data linkage and retrieval techniques required for smooth interoperability, which poses difficulties for the utilisation of information through BIM over an asset's life cycle (McArthur, 2015). Furthermore, the nature of information from BIM and AIM systems and its fragmentation is another barrier (Pärn et al., 2017). 
In an attempt to address some of these issues, Mirarchi et al. (2018) demonstrate the value of information in a knowledge-based asset environment. However, the study indicates a need for more research on how information can generate value for built assets in a virtual AM environment. Similarly, McArthur (2015) suggests the need for asset owners to identify the necessary information content required for asset operations to guide information utilisation over the facility's life cycle. Therefore, further research is needed to develop methodical approaches for efficient information management and the growing use of BIM in AM (Pärn et al., 2017).

Summarily, the review of literature has shown a lack of understanding amongst asset owners of the strategy and implementation approaches of BIM-based AIM. Furthermore, it highlights that identifying information value within organisations still remains a subject of debate. Also, the literature review revealed the need for further research on how information can generate value for built assets in a virtual BIM-based AM environment. 


\subsection{METHODOLOGY AND RESEARCH QUESTION}

\subsection{RESEARCH QUESTIONS}

This study aims to investigate the information asset content that drives business value in $\mathrm{AM}$ and how asset information is collected, organised, stored, controlled, analysed, secured, shared and reported within a virtual BIM-based AIM system for strategic management-based decisions. The study will address the following research questions:

- How does the information content captured from physical assets generate business value in $\mathrm{AM}$ and which aspect relates to BIM?

- How does the information content deliver business value for built assets?

\subsection{RESEARCH METHODS}

This is a case study research conducted in a large building design, consultancy and software company in Finland to investigate the information asset content that drives business value in AM. Granlund provides services to over 1,000 clients and asset owners in about 30 countries. Their headquarters is located in Helsinki, Finland and they have offices in Scandinavia, UK, Asia and the Middle East. This research is focused on the activities of four departments responsible for handling client asset portfolios, data analytics and reporting for strategic decision-making. These are Granlund Manager, Building Automation, Digital Property Services and Innovation And Development. Yin (2003) suggests that case studies are appropriate for studying the activities and decisions of individuals, organisations, processes and events. The study adopts exploratory and descriptive research designs (Saunders et al., 2012). Exploratory research methods are appropriate for investigating BIM business value and identifying variables, while descriptive research methods are suitable for analysing the AIM system and characterising its elements. Furthermore, a purposive sampling method is used for the case and participant selection. This is because qualitative studies are in-depth investigations that focus on relatively small samples or single cases that are selected purposefully (Patton, 2002). A classification of purposive sampling, which is operational construct sampling, is used based on the theoretical constructs of the study that focuses on investigating BIM business value in AM through a real-life design. This strategy is suitable for investigations where the sample population of BIM adopters in AM is not 
known, thereby making random sampling impracticable (Patton, 2002). The following criteria is considered in the participant selection for the study:

- Participants are senior personnel of the four departments investigated.

- Participants are both senior and junior personnel who interfaced with clients.

- Participants are senior personnel in asset monitoring and optimisation operations.

- Participants are senior personnel in the technology and innovation department who are responsible for innovation and future developments.

- Participants had an advanced level of knowledge and understanding of BIM in AM and operations

Checking for validity was done through two activities: participant validation and data triangulation. Moreover, the study outcome was communicated to the participants for assent (Saunders et al., 2012). Data triangulation validity was conducted during data collection through the utilisation of multiple sources of data (Patton, 2002).

The study is conducted in two stages: the literature review and case study research. The first stage is the literature review, where studies within the domains of BIM, AIM and information value were examined. The second stage is the case study research, where the study investigates and documents the processes of capturing and analysing asset data for strategic reporting. This stage involved two main activities, namely, interviews and document analysis. The technique of semi-structured interviews is used to collect data. The interview questions are developed from a systematic method of thematic analysis (Boyatzis, 1998). The questions are based on a list of themes, which varied from interview to interview due to the varying work nature of the respondents (Saunders et al., 2012). Interviews helped to obtain detailed information on the processes relating to collecting and reporting of asset data to clients for decision-making. Secondly, document analysis is conducted to review the information content, data formats, data sources, operational workflows and benefits derived from using Granlund AIM and BIM systems. Figure 1 shows the methodological process of the study. 


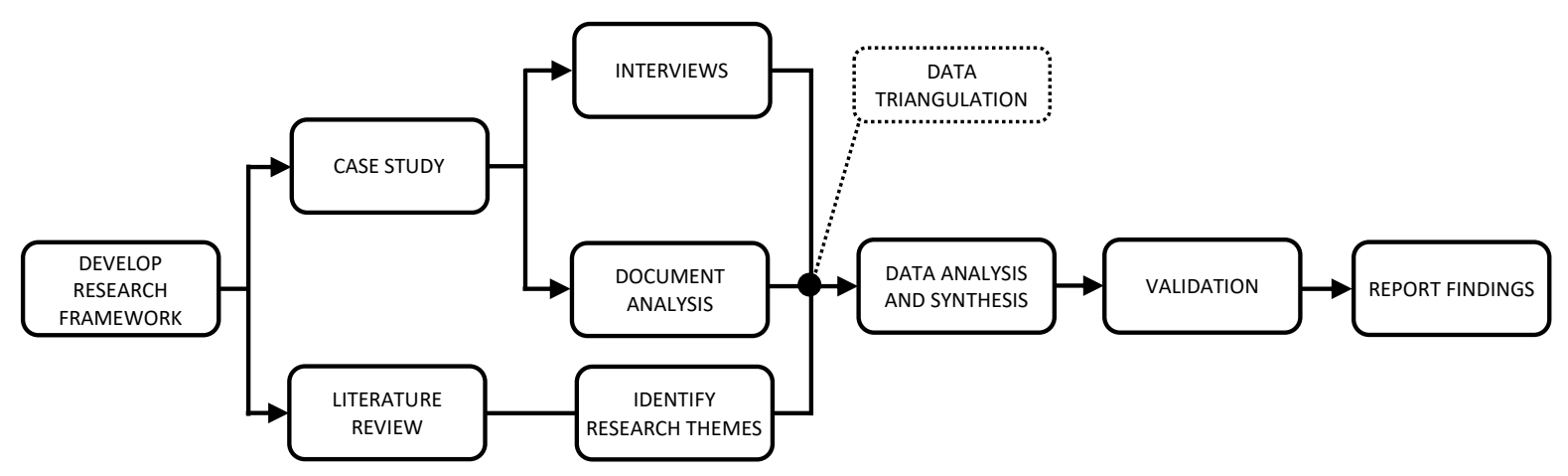

Figure 1: Research methodology

\subsection{DATA COLLECTION AND ANALYSIS}

The study adopts a qualitative approach towards data collection and analysis. Qualitative findings emanate from three types of data collection approaches: interview, observation and document analysis (Patton, 2002). This study uses interviews and document analysis in primary data collection. Seven sets of interviews were conducted and nine respondents were interviewed from different departments in Granlund: three respondents from Granlund Manager, two respondents from Building Automation, two respondents from Digital Property Services and two respondents from Innovation and Development. This sampling ensured that at least one person is interviewed from the operational, management and strategic reporting of asset information in Granlund. After the interviews, NVivo software is used for the transcription, coding and data analysis (Bazeley and Jackson, 2013). Thematic analysis was conducted during the literature review to establish themes. This is a technique of classifying and reporting patterns within data (Boyatzis, 1998). The process started by identifying patterns in the literature, which were arranged into themes. The themes further guided the development of the interview questions for the study. Collected data are then coded into main and sub-codes and then given descriptions. Coding is a technique of cataloguing data for analysis (Boyatzis, 1998). Consequently, the theory-driven analytical themes provided a theoretical structure for developing data-driven descriptive themes or categories (Thomas and Harden, 2008). The higher-order thematic categories were used to classify one or more codes in the data analysis and discussion. The analysed data are reported in categories and notations. Table 1 shows the summary of the thematic analysis. 
Table 1: Data themes, codes, categories and notations

\begin{tabular}{|c|c|c|c|c|}
\hline $\mathbf{S} / \mathbf{N}$ & THEME & CODE & CATEGORY & NOTATION \\
\hline \multirow[t]{2}{*}{1} & \multirow{2}{*}{$\begin{array}{l}\text { Organisational } \\
\text { Asset } \\
\text { Information } \\
\text { Management } \\
\text { Strategy }\end{array}$} & AIM Strategy & Section 4.2 & $\begin{array}{l}\text { Granlund's AIM } \\
\text { Strategy }\end{array}$ \\
\hline & & BIM Strategy & Section 4.3 & $\begin{array}{l}\text { Granlund's BIM } \\
\text { Strategy }\end{array}$ \\
\hline \multirow[t]{6}{*}{2} & \multirow{6}{*}{$\begin{array}{l}\text { Asset } \\
\text { Information } \\
\text { Management }\end{array}$} & Data Formats & Section 4.5.1 & $\begin{array}{l}\text { Asset Data Collection, } \\
\text { Formats and Sources }\end{array}$ \\
\hline & & Data Requirements & Section 4.4 & $\begin{array}{l}\text { Asset Information } \\
\text { Requirements }\end{array}$ \\
\hline & & Data Sources & Section 4.5.1 & $\begin{array}{l}\text { Asset Data Collection, } \\
\text { Formats and Sources }\end{array}$ \\
\hline & & Data Analysis & Section 4.5 .3 & Asset Data Analysis \\
\hline & & Data Reporting & Section 4.5.4 & Asset Data Reporting \\
\hline & & $\begin{array}{l}\text { Data Sharing and } \\
\text { Storage }\end{array}$ & Section 4.5 .2 & $\begin{array}{l}\text { Asset Data Transfer, } \\
\text { Handling and Storage }\end{array}$ \\
\hline \multirow[t]{4}{*}{3} & \multirow[t]{4}{*}{ Business Value } & Information Value & Section 4.6 & BIM Business Value \\
\hline & & Client Value & Section 4.6 & BIM Business Value \\
\hline & & BIM Business Value & Section 4.6 & BIM Business Value \\
\hline & & Challenges & Section 4.7 & $\begin{array}{l}\text { Challenges of the } \\
\text { System }\end{array}$ \\
\hline
\end{tabular}




\subsection{RESULTS: CASE STUDY}

\subsection{INTRODUCTION OF THE CASE}

Granlund (https://www.granlund.fi) is a design, consultancy and software company in Finland. This company has been implementing BIM solutions for clients globally. They offer a wide range of AIM solutions with analytics that provide tools for asset managers to plan and execute tasks. The utilisation of the BIM systems together with AIDC technologies and IoT integration empowers asset managers with an ability to monitor and evaluate their assets in almost real-time.

\subsection{GRANLUND'S AIM STRATEGY}

Granlund has developed an AIM strategy for managing its asset data. This is divided into three sections of organisational management, namely; operational, tactical and strategic levels (Figure 2).

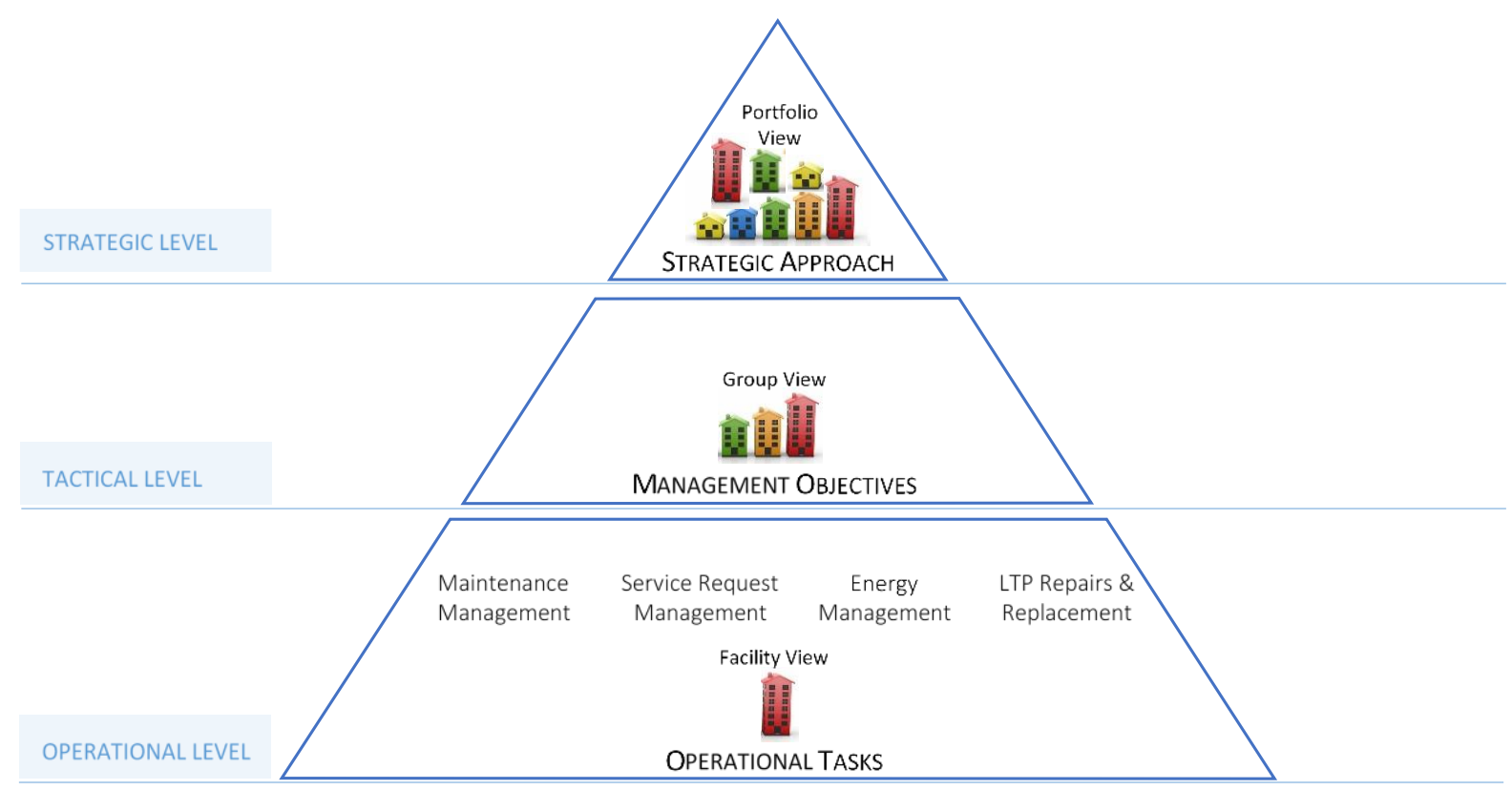

Figure 2: Granlund asset management levels adapted from Hänninen (2011)

\subsection{GRANLUND'S BIM STRATEGY}

Granlund's BIM strategy aims to provide a platform for the effective creation of information assets where the facility and end-user will communicate by connecting through silos of information within a client organisation. This is presented in seven aspects shown in Figure 3. 


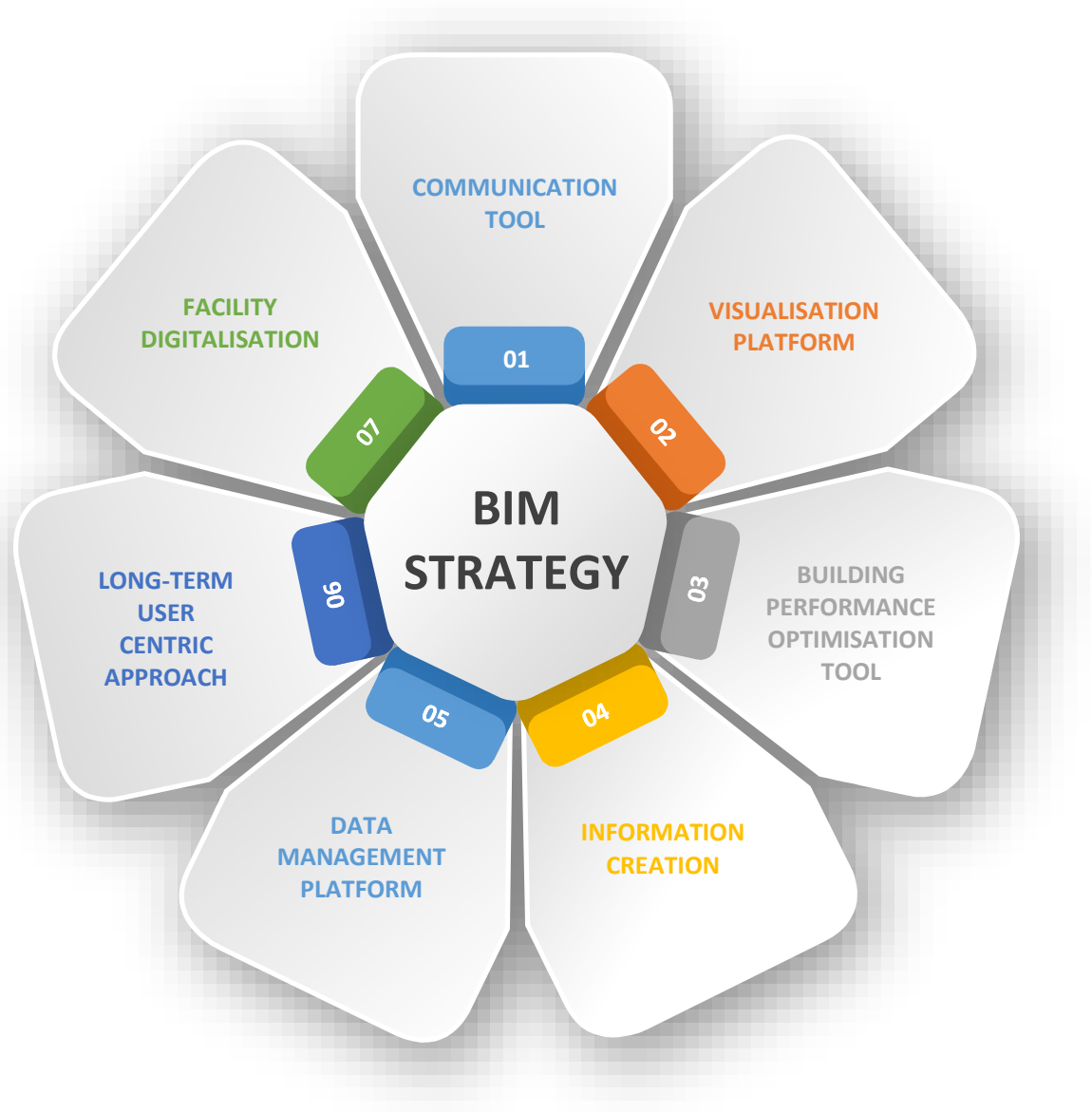

Figure 3: Granlund's BIM strategy

Furthermore, Granlund has developed a roadmap for its innovation journey to articulate how it forecasts the development of BIM systems and the responsiveness of the facility as technology continues to develop. The first is the basic functionality where the BIM systems act as a platform for visualisation. At this stage, it becomes a connection node between the building management systems (BMS) and users to evaluate facility performance. The next phase denotes its evolution into a data analysis and optimisation platform, which would enable asset managers to use IoT data generated by the facility. The amount of asset data generated by built assets is expected to increase exponentially, therefore, a platform with different user interfaces for aggregating that data will be necessary. The next level is where a reporting facility emerges through the big data. Large sets of information will be available for the asset owner, which would enable the facility to achieve this level of maturity. The next phase is the predictable facility where algorithms are developed to predict asset performance or failure. This would change the model of asset interventions from a need-based to a demand-based approach. Subsequently, a learning facility emerges through the harnessing of predictive data and 
the further development of algorithms. The final stage would involve the development of a thinking facility. This is to have a facility that could reason through the large data sets in order to optimise performances. The stages are shown in Figure 4.

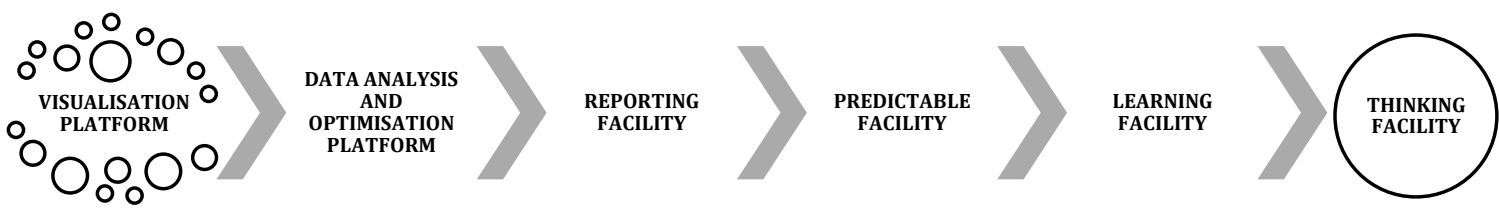

Figure 4: Granlund's innovation roadmap

\subsection{ASSET INFORMATION REQUIREMENTS}

Granlund has a formal process for documenting and analysing asset information and the template contains key performance indicators (KPI), which guide the data collection processes. Furthermore, specific requirements on building details, energy data, contract details, planning details and performance optimisation are collected from individual assets. Figure 5 contains the parameters and priorities of the asset information requirements for the Granlund AIM system.

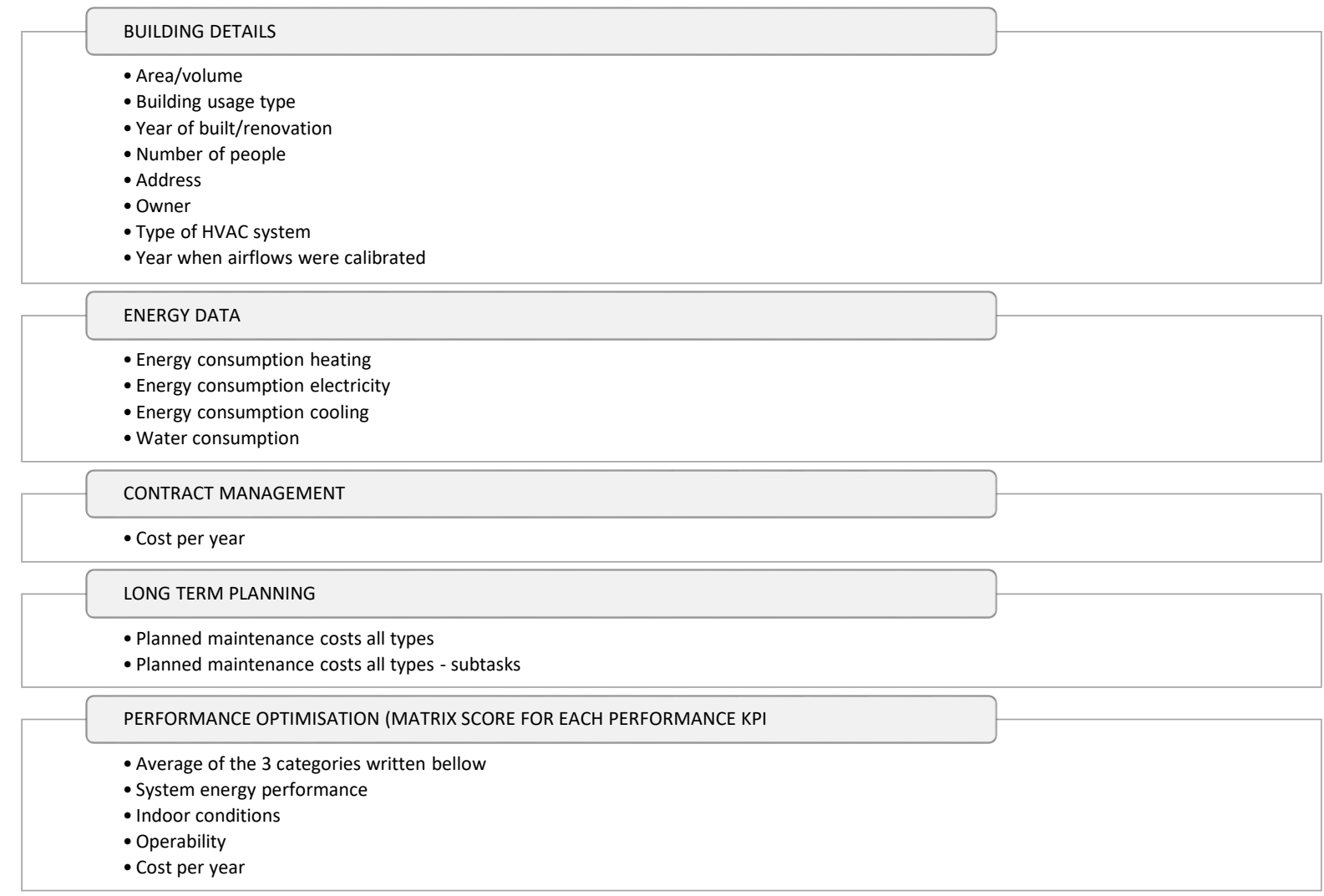

Figure 5: Parameters and priorities for asset information requirements 


\subsection{IMPLEMENTATION/REPORTING PROCESS}

At the beginning of the implementation process, Granlund developed a four-level reporting process for its AIM strategy: asset data collection, formats and sources; asset data transfer, handling and storage; asset data analysis; and asset data reporting. This is shown in Figure 6.

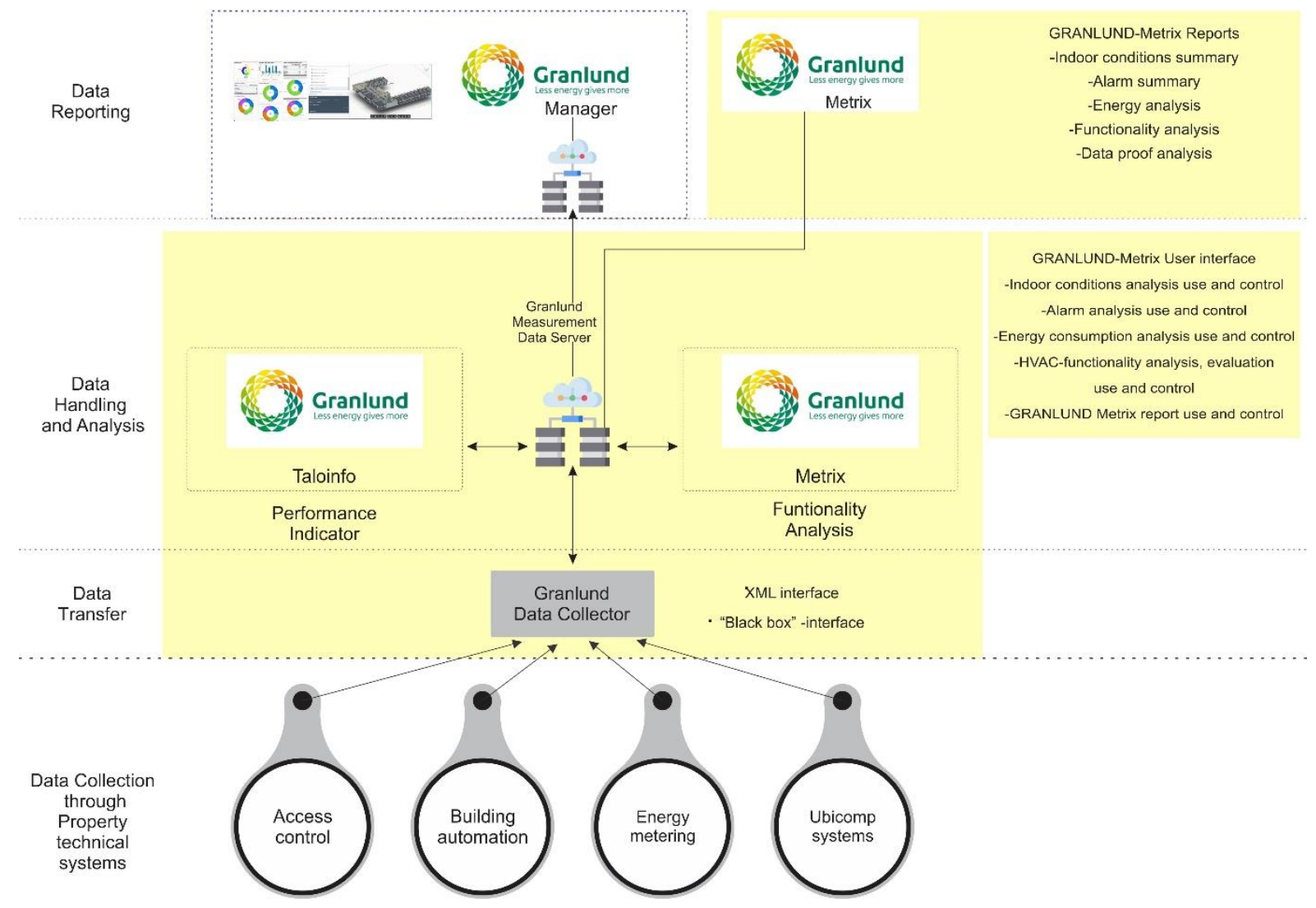

Figure 6: Granlund's AIM reporting process adapted from Hänninen (2011)

\subsubsection{ASSET DATA COLLECTION, FORMATS AND SOURCES}

This is the level at which asset data are collected through sensors and manual input from every work-station that is responsible for asset maintenance. The data formats supported by the AIM and BIM systems are presented in Appendix. Asset data are sourced in Granlund from two main points of supply; static and dynamic. Typically, static asset data are documented information from industry foundation classes (IFC) models and maintenance manuals. Dynamic information is data from IoT sensors, building automation systems and feedback from end-users. A combination of both static and 
dynamic information forms the main source of data for the facility's digital twin. The data sources are shown in Figure 7.

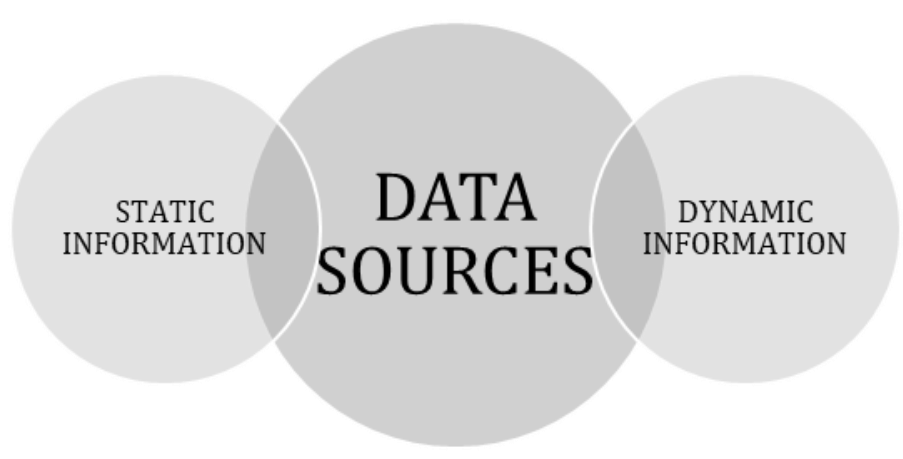

Figure 7: Granlund's data sources

The asset database structure for dynamic data, which is generated from built assets, has two main source points: alarm and measures. This is shown in Figure 8.

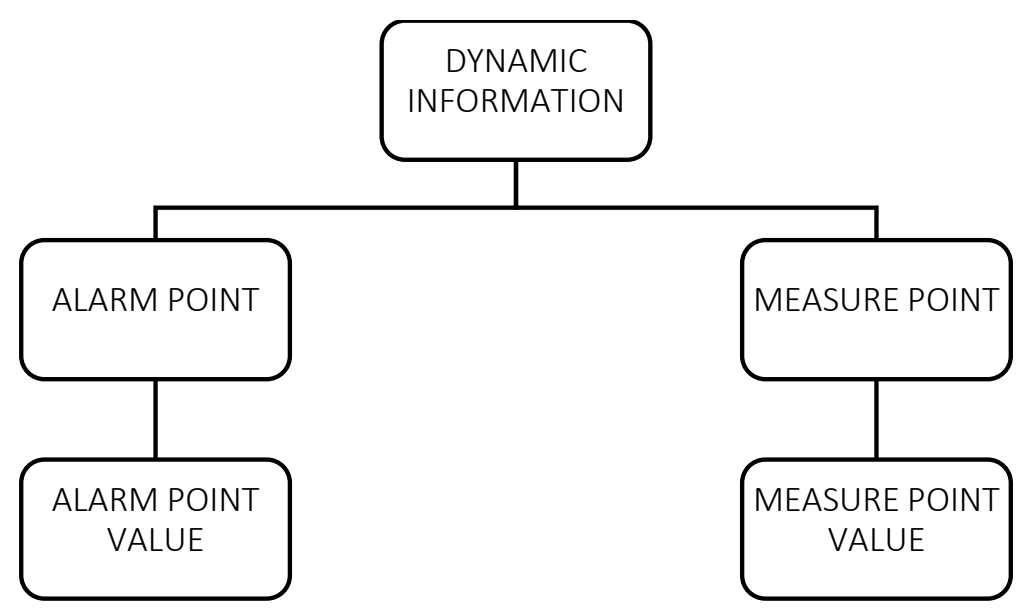

Figure 8: Granlund's asset database structure for dynamic information

\subsubsection{ASSET DATA TRANSFER, HANDLING AND ANALYSIS}

Data are transferred across the AIM and BIM modules in approved formats and stored in a database, which is linked to Granlund Manager. Data handling is done using the Granlund Manager user interface. Data are collected by setting a software layer over the BMS in each building, which is sent in batches to the cloud service or analytics. On the other hand, data analytics are achieved through the Granlund Metrix module, which calculates ratios, performance indexes and deviations, and conducts other forms of analysis. The Granlund Metrix module can perform analytics at the building, floor, room or desk level. Thus, if the systems are able to report at an accurate level, then there is 
more value for the asset owner in terms of the types and levels of analysis that can be performed. The level of analysis is shown in Figure 9.

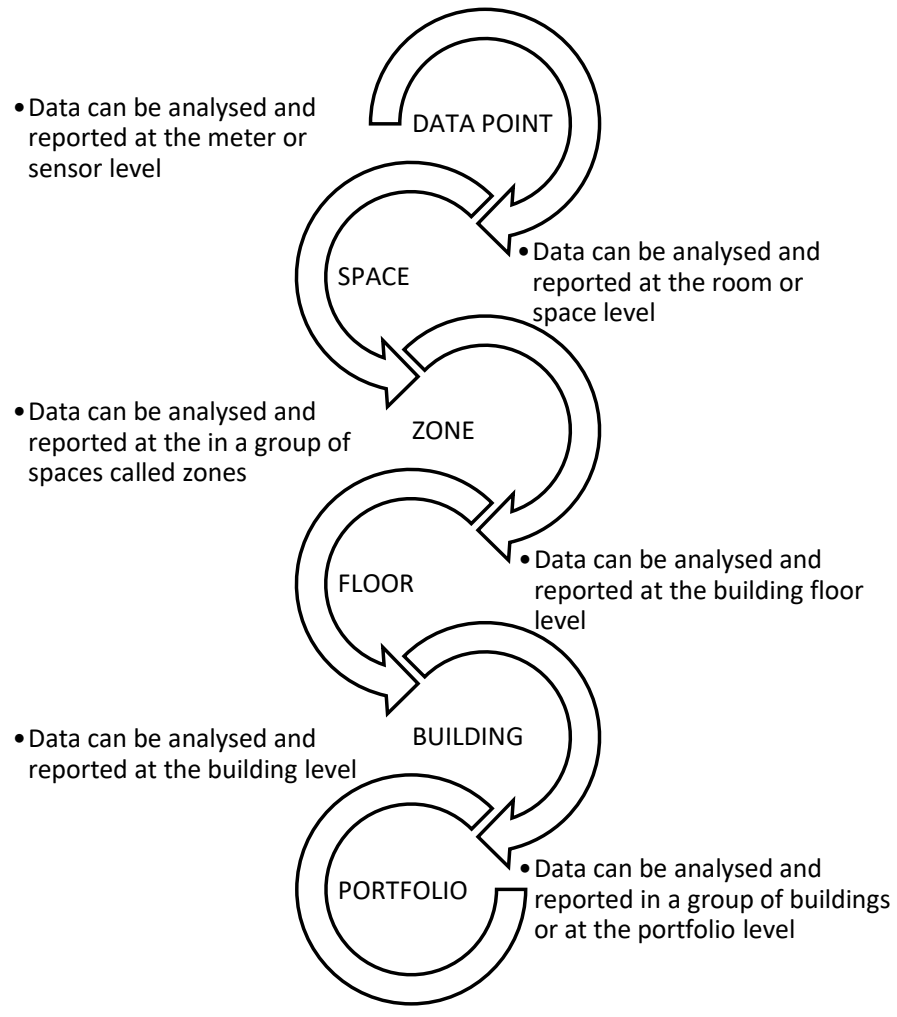

Figure 9: Levels of data analysis

There are three major classifications of analysis carried out by the AIM system at Granlund in the form of KPI: energy performance, operability and long-term planning. On the other hand, Granlund has adopted the approach of using IFC when reviewing static data for analytics. This is because IFC is a snapshot of static information contained in the digital representation of the facility. Similarly, dynamic BIM data are visualised through the digital-twin module.

\subsubsection{ASSET DATA REPORTING}

The report assembler of the Granlund Manager produces the summaries of all appraised assets within the built asset or building portfolio. Typically, data are generated hourly, and then analysed and reported the day after. Furthermore, asset data sourced from the Cloud can be reported more in real-time at the sensor level. This is shown in Figure 10. 


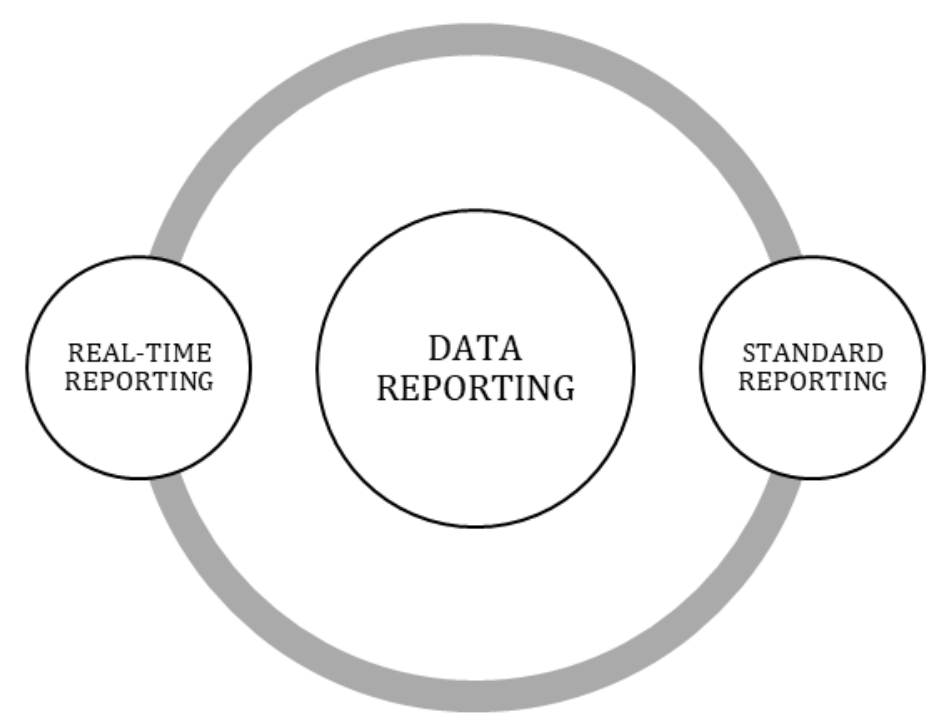

Figure 10: Data reporting types

On the Granlund Manager user interface, the asset manager can view the building performance. There is an index for energy efficiency, functionality and the indoor environment. The index is a score that measures building performance. All these processes have sub-processes with sub-indexes all the way to the sensor level.

\subsection{BIM BUSINESS VALUE}

The study identifies six aspects of BIM business value that may be of benefit to the asset owners' business objectives and ecosystem, which are: management, commerce, efficiency, industry, user and technology value (Figure 11). In an earlier study, Munir et al. (2018) present a BIM value realisation framework, which suggests how the tangible and intangible values presented in this section could be evaluated. 


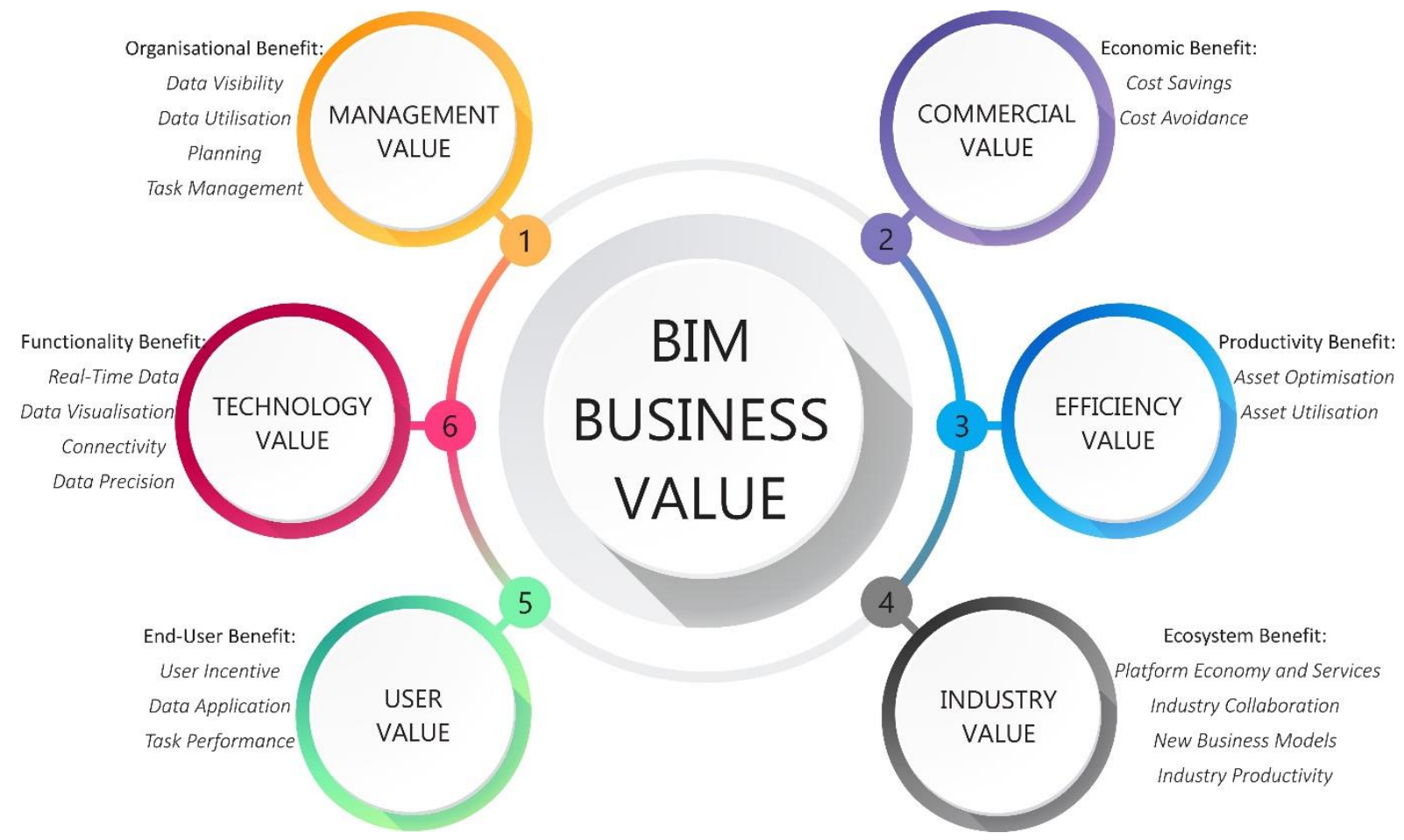

Figure 11: BIM business value in AM

\subsubsection{MANAGEMENT VALUE}

From the management perspective, BIM delivers value for the asset owner at the strategic, tactical and operational levels. The benefits identified here are: the effective use of data, the better planning of spaces, improved asset data visibility and task management and an enhanced maintenance culture. The management value identified here is mostly intangible (Nogeste and Walker, 2005). At the strategic, tactical and operational levels, BIM can influence the effective use of data within the organisation. The use of BIM systems helps the asset manager to better use data by effectively monitoring key assets and by bringing out deviations in asset data. Secondly, at the strategic and tactical levels, the BIM systems can enhance general planning and improve organisational set-up. Space allocations and travel path analysis can be conducted using the BIM systems together with BMS and IoT data to plan the workspace to be used more efficiently. For example, an asset owner may require additional two-person meeting rooms for a particular purpose whilst a five or ten-person meeting room exists that is not used. Thus, data from the systems can be used to identify the least used room so that it can be re-assigned. Thirdly, management value is derived through the improved visibility of asset data and 
enhanced task management. Using the BIM systems, an asset manager can gain a deeper insight into detailed asset data including service areas, asset locations and maintenance history. This data can help the asset manager to develop an effective asset maintenance plan. Asset managers are able to track new service requests, open requests, task considerations and the number of completed tasks over a particular period. Also, the asset manager can use the BIM systems to monitor service provider portfolios. Fourthly, at the operational level, the BIM systems can improve the culture of planned preventive maintenance by facilitating asset maintenance through data. For example, there could be two air handling units in the same building; one running for $300 \mathrm{~h}$ per month and the other running for $700 \mathrm{~h}$ per month. Normally, both are serviced with the same frequency and at the same intervals. Having access to this type of data will assist the asset manager in identifying which asset is under-maintained, thereby, improving the maintenance culture of the organisation.

\subsubsection{COMMERCE VALUE}

BIM can deliver commercial value for the asset owner through improved financial performance and profitability. Commercially, the benefits to the asset owner are twofold; cost savings and cost avoidance. The value realised here are both tangible and intangible (Nogeste and Walker, 2005). BIM systems can bring about cost savings by supporting the asset manager in improving the running and maintenance of assets, thereby, bringing financial benefits to the business. For example, in one case, the data analytics module (Granlund Metrix) detected some air-handling units that were running for $24 \mathrm{~h}$ instead of the initial $17 \mathrm{~h}$ daily programming. The problems were corrected and savings were realised from the solution. Instances such as these bring direct cost savings to the business. Other aspects of BIM business value that bring about cost savings include: effective space planning, checks to the asset operational hours and the planning of maintenance schedules. These respectively enable enhanced space efficiency, reduced down-time hours and an enhanced asset life cycle. On the other hand, cost avoidance is a significant benefit that BIM brings, although it is difficult to quantify. Cost avoidance involves any added functionality or pre-emptive actions as a result of utilising the BIM systems that enable the asset owner avoid having to incur costs. Effective monitoring of assets and correcting deviations are actions that save costs as a result of using the BIM systems. Thus, if the deviations are not corrected, it could cost the asset owner more on 
energy and asset maintenance in the long run. Another aspect of cost avoidance is by optimising the systems to operate so that there are no on-call alarms. The elimination of these alarms would typically bring about cost avoidance because the asset owner would not incur the costs of having specialists to check the physical assets during on-call hours, which averages between $€ 200$ and $€ 300$. As a result, there is commercial business value to the asset owner if the BIM systems can be optimised to operate efficiently.

\subsubsection{EFFICIENCY VALUE}

Efficiency value from enhanced operations in AM is another aspect of BIM business value that can be derived by the asset owner. The benefits identified here are asset optimisation and improved utilisation of the building. The value realised here is mostly intangible, but there are also tangible aspects (Nogeste and Walker, 2005). The BIM systems have the potential to provide reliable data to the asset manager through the Granlund Metrix module, which supports asset optimisation by highlighting those systems that are operated correctly, and those that are not. The BIM systems act as an activity bracelet for the entire building by monitoring the asset condition and performance, including the visibility of historic asset data. Also, through the BIM systems, the asset manager may use a remote connection to make changes, correct set points and/or amend system time schedules. On the other hand, the asset owner can derive efficiency value through the data provided by the BIM systems to measure the utilisation of the building. A combination of more than one functional reading could be used to measure how the building is operated. For example, the first set of data from a lighting presence detector, combined with the second from a temperature sensor and the third from a meeting room booking system may give the asset manager a fourth functionality that measures utilisation. These data sets give the asset manager the opportunity to create value through the effective measurement of management and operational KPI.

\subsubsection{INDUSTRY VALUE}

Another element of BIM business value is industry value. This is where value can be derived exclusively or collectively as a result of corresponding functionalities, services and professions in the AEC industry. Some of the benefits identified here are: platform economy and services; supporting collaboration between companies; development of new business models and improvement of overall industry productivity. The value 
realised at this level is mostly intangible but there are also tangible aspects (Nogeste and Walker, 2005). The asset owner can derive BIM business value from the platform economy and services through smart cities and IoT data. As facilities become more and more digitised, there are many national strategies and policy documents to digitalise the built environment (Kassem et al., 2015). Asset owners with highly matured BIM programmes will be able to connect to the opportunities that platform economies provide to the AEC industry. Platform and sharing economies have the potential to reduce operational and transaction costs in the AEC industry through flexibility and sharing. Secondly, BIM systems provide an opportunity for collaboration with other stakeholders with the aim of improving value streams through the addition of more functionalities in collecting, analysing and reporting asset data. The first part is achieved by automating the maintenance process, starting from the dispatch of work-orders right through the tendering process including invoicing and sign-offs. The second part is achieved by providing the opportunity to collaborate with technical partners and start-ups for asset optimisation. The BIM systems help to create collaborative "win-win" environments for all actors including the potential benefits of increased productivity, lower costs and higher quality by eliminating the traditional adversarial "win-lose" relationships of the AEC industry. Thirdly, the utilisation of BIM systems could derive business value through the development of new business models in the AEC industry. The systems will act as an interaction node for navigating through the large sets of information assets between industry actors and building or city digital twins. The increase in quality data from the BIM systems could help to develop new business models that will explore asset data with reference to the facility geometry, albeit, for the benefit of the asset owner. Similarly, the provision of other services could serve as enablers for external business models such as smart grid solutions, real-time data and maintenance on-demand. Fourthly, another aspect of industry-related BIM business value is the potential improvement of overall industry productivity. The BIM systems provide a platform for supporting start-ups in the building services sector that will use asset data and analytics in optimising building performance. These start-ups will connect to the facility and could add functionalities such as pre-testing, pre-fabrication, self-diagnostics and machine learning to improve the overall service delivery of the industry. 


\subsubsection{USER VALUE}

BIM can drive business value for individual actors that use the systems to perform daily tasks. The business value identified here are: user incentive, multiple user data perspectives and higher employee productivity. However, user value realised at this level is mostly intangible (Nogeste and Walker, 2005). The BIM systems provide an incentive for users because they save time, simplify tasks and provide accurate data. The systems report KPI data that are specific to the users and their daily tasks. This user-centric view creates dependability on the systems by reporting KPI that focus on organisational business activities. Secondly, data produced from the BIM systems allow for multiple perspective analysis of the same asset data by different professionals within the same organisation. For example, analysis conducted by Granlund aimed at analysing the utilisation of a facility by using lighting sensors in a building had the following outcomes: the team manager was focused on appraising productivity and punctuality; the energy manager was focused on energy efficiency and the space manager was focused on space efficiency and analysing options in relation to room and space allocations. The data set had enough information for all these professionals to make reasoned judgements. Thirdly, another aspect of user-related BIM business value is enhanced employee productivity as a result of accurate data, improved data delivery and task automation. The BIM systems have the potential to automatically filter and sort data for user task execution. The ability of the BIM systems to provide the right information at the right time for the right user to perform a task creates value for the end-user.

\subsubsection{TECHNOLOGY VALUE}

Technology value is an element of BIM business value that the asset owner can benefit from. The benefits identified here are real time data from the 3D building information models, the visualisation of asset data, data connectivity and a precise level of reporting. However, technology value realised at this level is mostly intangible (Nogeste and Walker, 2005). Technologically, the BIM systems deliver crucial business value by enabling the asset manager to analyse asset condition and performance in real-time. For example, if the temperature is too high or too low, the asset manager should know immediately and not when the reports come in a day, week or month later. Another benefit that technology brings is data visualisation. The BIM systems provide an interface for visualising asset data either in dropdown lists or in 3D views. This visual interface is crucial because it 
would be impossible for the asset manager to filter and use all asset data coming from the BMS and IoT using traditional methods such as spreadsheets. Also, the system colour codes are visual aids that help the asset manager to instantly comprehend summary reports at the strategic level for prompt decision-making. The green, yellow, red and blue lights indicate complete, in-progress, overdue and scheduled tasks, respectively. Data connectivity is another business value that technology brings to the asset owner. The BIM systems support the sharing of data and stimulate collaborative working by bridging data connectivity between diverse systems and by breaking down the silos of information within organisations and across the supply chain. Furthermore, data connectivity such as remote access enables the asset manager to simulate the building in the Cloud, thereby making it easier to collect data, connect systems, analyse and optimise assets. Lastly, the BIM systems provide precise levels of analysis and reporting. This capability enables the asset manager to answer management-related queries that would be impossible to achieve using traditional methods. 


\subsection{DISCUSSION}

BIM-based initiatives are largely focused on the design and construction phases. However, there is considerable potential for asset owners to obtain business value from BIM during asset operations. The main contribution of this study is to demonstrate that value can be derived from the effective management of information assets within an organisation. Also, issues surrounding AIM for asset owners such as strategy, information management, reporting process and business value have been addressed in this study. The study identifies: (a) the elusive value of information, (b) lack of understanding of BIM-based AIM implementation, (c) and technical and operational challenges of BIMbased AIM as premises for such lack of awareness.

Furthermore, some studies have been conducted on AIM from the perspective of data quality (Koronios et al., 2005), interoperability with BIM systems (Talamo and Bonanomi, 2015), frameworks for the development of asset information models (Patacas et al., 2016) and organisational strategy (Ouertani et al., 2008). None of the aforementioned studies have addressed AIM in relation to BIM business value in asset operations. This study has revealed that effective AIM through BIM has the potential to generate business value by identifying six typologies of BIM business value. Another contribution of the study is the identification of unique systems for the effective management of asset information content through three levels of management; strategic, tactical and operational. The results of the research show that the case study succeeded in effectively implementing BIM-based AIM processes in management and operational tasks during asset operations. 


\subsection{CONCLUSION}

The purpose of the study is to evaluate how asset information is collected, organised, stored, controlled, analysed, secured, shared and reported within a virtual AIM system for strategic management-based decisions. The study findings show that there is huge potential for BIM to deliver business value in AM. The study critiques the definitions of BIM and identifies AIM strategies within the literature, noting a lack of consensus on the true value of information. The study identifies the key techniques of managing asset data and how those data are reported for critical decision-making. Furthermore, the findings in this study can lead to three main conclusions. First, there is real value to be derived by the asset owner from the effective management of asset information. This helps to clarify doubts on whether there is value in implementing BIM in AM. Second, the research highlights that the value of BIM is not inherent but instead requires many other processes to deliver value to the organisation. The study has shown that there is the potential to conduct a wide range of analyses using building automation systems, AIM and BIM systems for asset optimisation, and that value lies at the end of the process. Finally, the research identifies six dimensions of value that BIM contributes to AM: management, commerce, efficiency, industry, user and technology value. 


\section{ACKNOWLEDGEMENT}

This is a collaborative study between University of Liverpool and Granlund OY as part of a PhD study. The following personnel contributed to the study; Ken Dooley, Veikko Martiskainen, Davor Stejelja, Tero Järvinen, Jennie Rusama, Mika Virkki, Teemu Hausen, Tuomas Laine and Francisco Forns-Samso. The authors acknowledge their immense contributions. 


\section{REFERENCES}

Aranda-Mena, G., Crawford, J., Chevez, A. and Froese, T. (2009) 'Building information modelling demystified: does it make business sense to adopt BIM?', International Journal of Managing Projects in Business, vol. 2, no. 3, pp. 419 - 434.

Bazeley, P. and Jackson, K. (2013) Qualitative data analysis with NVivo, $2^{\text {nd }}$ edition, London: Sage Publications Ltd.

Boyatzis, R.E. (1998) Transforming qualitative information: thematic analysis and code development, $1^{\text {st }}$ edition, Thousand Oaks: Sage Publications, Inc.

Boyes, G., Ellul, C. and Irwin, D. (2017) 'Exploring BIM for operational integrated asset management - a preliminary study utilising real-world infrastructure data', ISPRS Annals of Photogrammetry, Remote Sensing and Spatial Information Sciences. IV-4/W5: 12th 3D Geoinfo Conference 2017, 26-27 Octobe, Melbourne, Australia, 49-56.

Brous, P., Herder, P. and Janssen, M. (2016) 'Governing asset management data infrastructures', Procedia Computer Science 9, vol. 95, no. 1, pp. 303-310.

BSI (2008) Asset Management - Part 1: Specifications for the optimized management of physical assets - PAS 55-1: 2008, London: The British Standards Institution 2008; BSI Standards Limited 2008.

BSI (2014) Specification for information management for the operational phase of assets using building information modelling - PAS 1192-3:2014, London: The British Standards Institution 2014; BSI Standards Limited 2014.

BuildingSMART (2018) Infrastructure Asset Managers BIM Requirements: Version 1: Delivering the information 'Asset Managers' need and can trust using openBIM, BuildingSMART International, Available: https://www.buildingsmart.org/wpcontent/uploads/2018/01/18-01-09-AM-TR1010.pdf [23 Mar 2019].

Carayannis, E. (2004) 'Measuring intangibles: Managing intangibles for tangible outcomes in research and innovation', International Joumal of Nuclear Knowledge Management, vol. 1, no. 1, pp. 333-338.

Codinhoto, R. and Kiviniemi, A. (2014) 'BIM for FM: a case support for business life cycle', 11th IFIP International Conference on Product Lifecycle Management, 7-9 July 2014, Yokohama, Japan, 63-74.

Curtis, G. and Cobham, D. (2008) Business information systems: analysis, design and practice, $6^{\text {th }}$ edition, Essex: Prentice Hall: Pearson Education Limited.

Dave, B., Buda, A., Nurminen, A. and Främling, K. (2018) 'A framework for integrating BIM and IoT through open standards', Automation in Construction, vol. 95, pp. 35-45.

Eastman, C., Teicholz, P., Sacks, R. and Liston, K. (2011) BIM Handbook: a guide to building information modeling for owners, managers, designers, engineers and contractors, $2^{\text {nd }}$ edition, Hoboken: John Wiley \& Sons, Inc. 
Engelsman, W. (2007) 'Information assets and their value', In Proceedings of the 6th Twente student conference on IT. University of Twente. January 31-February 2, 2007, Enschede, Twente, Netherlands.

Guillen, A.J., Crespo, A., Gómez, J., González-Prida, V., Kobbacy, K. and Shariff, S. (2016) 'Building information modeling as assest management tool', IFAC-PapersOnLine, vol. 49, no. 28, pp. 191-196, Available: http://dx.doi.org/10.1016/j.ifacol.2016.11.033.

Hänninen, R. (2011) 'BIM in Design: BIM for efficient and sustainable operation', First Annual Conference in the Middle East Building Information Modeling (BIM) Vision, Strategy and Implementation, Abu Dhabi Men's College, 14-15th December 2011, Abu Dhabi.

Juan, D. and Zheng, Q. (2014) 'Cloud and open BIM-based building information interoperability research', Journal of Service Science and Management, vol. 7, Apr, pp. 47-56.

Kassem, M., Kelly, G., Dawood, N., Serginson, M. and Lockley, S. (2015) 'BIM in facilities management applications: a case study of a large university complex', Built Environment Project and Asset Management, vol. 5, no. 3, pp. 261-277.

Kelly, G., Serginson, M., Lockley, S., Dawood, N. and Kassem, M. (2013) 'BIM for facility management: a review and a case study investigating the value and challenges', Proceedings of the 13th International Conference on Construction Applications of Virtual Reality, 30-31 October 2013, London, UK, 191-199.

Koronios, A., Lin, S. and Gao, J. (2005) 'A data quality model for asset management in engineering organisations', Proceedings of the 10th InternationalConference on Information Quality (ICIQ 2005), Massachusetts Institute of Technology, Cambridge, USA.

Lin, S., Gao, J., Koronios, A. and Chanana, V. (2007) 'Developing a data quality framework for asset management in engineering organisations', International Journal of Information Quality, vol. 1, no. 1, pp. 100-125.

Li, J., Wang, Y., Wang, X., Luo, H., Kang, S.-C., Wang, J., Guo, J. and Jiao, Y. (2014) 'Benefits of building information modelling in the project lifecycle: construction projects in Asia', International Journal of Advanced Robotic Systems, Available: https://journals.sagepub.com/doi/pdf/10.5772/58447.

Love, P.E.D., Matthews, J., Simpson, I., Hill, A. and Olatunji, O.A. (2014) 'A benefits realization management building information modeling framework for asset owners', Automation in Construction, vol. 37, no. 1, pp. 1-10.

Love, P.E.D., Simpson, I., Hill, A. and Standing, C. (2013) 'From justification to evaluation: building information modeling for asset owners', Automation in Construction Volume, vol. 35, no. 1, pp. 208-216. 
Matarneh, S.T., Danso-Amoako, M., Al-Bizri, S., Gaterell, M. and Matarneh, R. (2019) 'Building information modeling for facilities management: A literature review and future research directions', Journal of Building Engineering, vol. 24.

McArthur, J.J. (2015) 'A building information management (BIM) framework and supporting case study for existing building operations, maintenance and sustainability', Procedia Engineering, vol. 118, pp. 1104-1111, Available: ISSN 1877-7058.

Mirarchi, C., Pinti, L., Munir, M., Bonelli, S., Brizzolari and Kiviniemi, A. (2018) 'Understand the value of knowledge management in a virtual asset management environment', eWork and eBusiness in Architecture, Engineering and Construction: Proceedings of the European Conference on Product and Process Modelling (ECPPM 2018), Copenhagen, Denmark, 12-14 September, 2018, Copenhagen, 13-20.

Moody, D. and Walsh, P. (1999) 'Measuring the value of information: an asset valuation approach', Copenhagen.

Munir, M., Kiviniemi, A. and Jones, S.W. (2018) 'Building Information Modelling (BIM) value realisation framework for asset owners', eWork and eBusiness in Architecture, Engineering and Construction: Proceedings of the 11th European Conference on Product and Process Modelling (ECPPM 2018), 12-14 September, 2018, Copenhagen, Denmark, 313-320.

Nogeste, K. and Walker, D.H.T. (2005) 'Project outcomes and outputs: making the intangible tangible', Emerald Publishing Limited, vol. 9, no. 4, pp. 55-68.

Ouertani, M.Z., Parlikad, A.K. and Mcfarlane, D. (2008) 'Towards an approach to select an asset information management strategy', International Journal of Computer Science and Applications, vol. 5, no. 3b, pp. 25-44.

Pärn, E.A., Edwards, D.J. and Sing, M.C.P. (2017) 'The building information modelling trajectory in facilities management: a review', Automation in Construction, vol. 75, pp. 45-55, Available: ISSN 0926-5805.

Parsanezhad, P. and Dimyadi, J. (2014) 'Effective facility management and operations via a BIM-based integrated information system', CIB Facilities Management (CFM) 2014 Conference, 21-23 May, 2014, Copenhagen, Denmark.

Patacas, J., Dawood, N. and Kassem, M. (2016) 'Supporting building owners and facility managers in the visualisation of an integrated Asset Information Model (AIM) based on open standards', Hong Kong.

Patton, M.Q. (2002) Qualitative evaluation and research methods, $3^{\text {rd }}$ edition, Thousand Oaks: Sage Publications.

Saunders, M., Lewis, P. and Thornhill, A. (2012) Research methods for business students, $6^{\text {th }}$ edition, Harlow: Pearsons. 
Succar, B., Sher, W. and Aranda-Mena, G. (2007) 'A proposed framework to investigate Building Information Modelling through knowledge elicitation and visual models', Proceedings of the Australasian Universities Building Education Association (AUBEA 2007), 4-5 July, Melbourne, Australia.

Talamo, C. and Bonanomi, M. (2015) 'Methodological experimentation: proposal of a datasheet template for FM activities in the BIM environment', in Knowledge management and information tools for building maintenance and facility management, Switzerland: Springer International Publishing.

Teicholz, P. (2013) BIM for facility managers, $1^{\text {st }}$ edition, Hoboken: John Wiley \& Sons, Inc.

Thomas, J. and Harden, A. (2008) 'Methods for the thematic synthesis of qualitative research in systematic reviews', BMC Medical Research Methodology, vol. 8, no. 1, July, pp. 8-45.

Tse, T.K., Wong, K.A. and Wong, K.F. (2005) 'The utilisation of building information models in $\mathrm{nD}$ modelling: a study of data interfacing and adoption barriers', ITcon, vol. 10, pp. 85-110.

Yin, R.K. (2003) Case study research: design and methods, 3 $3^{\text {rd }}$ edition, Thousand Oaks: Sage Publications, Inc. 


\section{APPENDIX A: SUPPORTED DATA FORMATS}

\section{APPENDIX A1: DATA FORMATS}

Supported building automation systems (per 1.1.2018), usually no more than 5-year-old systems:

- Arcada

- Atmostech

- BuildingEQ

- Citect

- Cozify

- Computec CSV \& XLS

- DEOS

- Siemens Desigo \& Desigo Web \& EMC

- Egain

- Fidelix

- Honeywell Symmetre \& EBI

- Metrix XML (Granlund format)

- OBIX

- RFSensit

- Simap

- Schneider Smartstruxure \& Vista

- $\quad$ Trend 963

- Visonic

\section{APPENDIX A2: TYPOLOGY OF DATA REQUIRED}

For the possible heat recovery and heating \& cooling network efficiency calculations:

- Outdoor temperature $\left({ }^{\circ} \mathrm{C}\right)$

- Supply air temperature after the heat recovery $\left({ }^{\circ} \mathrm{C}\right)$

- Extract air temperature $\left({ }^{\circ} \mathrm{C}\right)$

- Depending on the heat recovery type one of the following

- Heat recovery valve position (\%)

- Heat recovery damper position (\%)

- Rotation speed of the heat recovery wheel (\%)

- Temperature measurements from all heating / cooling networks $\left({ }^{\circ} \mathrm{C}\right)$

- Valve positions from all heating / cooling networks (\%)

For the AHU time schedule efficiency:

- Status (on/off) or the rotation speed of the supply air fan (Hz)

- Night ventilation and time lag switch status if available 
For the indoor conditions:

- Indoor temperature measurements $\left({ }^{\circ} \mathrm{C}\right)$

- Indoor humidity measurements (Rh)

- Pressure measurements (Pa)

- Carbon Dioxide measurements (CO2)

- Volatile organic compound measurements (VOC)

\section{APPENDIX A3: REMOTE CONNECTION SPECIFICATIONS}

Remote connection specifications:

- Minimum of DSL2 / ADS2L+ connection

- Access to the computer via Teamviewer, VNC, RDP or other remote monitoring software (Granlund can provide Teamviewer)

- Access right to Windows admin and the BMS system admin

- Firewall ports opened for ftp data transfer 